\title{
Constructing a DC Brushless Motor- an Experiential Engineering Clinic Activity for Mechanical Students
}

\author{
Samar Mohamed, Neil Griffet and Sanjeev Bedi \\ University of Waterloo \\ samar.mohamed@uwaterloo.ca
}

\begin{abstract}
The Engineering Ideas Clinic initiative at the University of Waterloo focuses on designing, developing and implementing learning activities provide students with authentic, applied and hands-on experiences which integrate their learning, and expose them to genuine applications in support of their engineering science content.

This paper focuses on "Constructing a Brushless DC Motor" activity which was piloted for second year Mechanical students in their "Electromechanical Devices \& Power Processing" course. The main motivation behind designing this activity is the fact that the principles of electromagnetism are often taught in an abstract way, and students can struggle to link the concepts with real life applications. Hence the authors have developed this activity to materialize these abstract concepts to the students.

Students in teams of three constructed a brushless DC motor, verify its construction and test its operation. In this activity students applied the principles in an experiential fun activity, compared the performance of their motors and worked collaboratively in teams.

In this paper, the authors will share their experience in developing and running this activity. They will also share their observations on the students' reaction and learning experience, as well as some comments from colleagues.
\end{abstract}

Keywords: Learning Electromagnetics, Knowledge Application, Experiential Learning, Reflection, Team Work, Giving and Receiving Feedback, Active Learning, Ill-defined problems.

\section{INTRODUCTION}

Electromagnetism is considered an abstract and cognitively demanding topic, hence it is very difficult for students to materialize and be comfortable with [1]. Lots of efforts have been made by physics educators to resolve this issue. One of the proposed solutions was to include visualizations or animations in the teaching and learning of abstract complex topics [1] ads well as augmented reality tools [2]. Another proposed solution was to use the flipped classroom method which allows the students to go through the dry material online and come to class ready to discuss the ideas and solve examples with the instructor [3].

Mayer had three assumptions on how people learn. In the first one, knowledge is assumed to be represented and manipulated through both the visual channel and the auditory channel. Mayer also assumed that the channels can become overloaded when a large volume of spoken words or pictures are presented. Mayer's third assumption, which is the base of the work presented in this paper, is called active processing, which assumes that learning occurs when students engage in active learning [4]. These active learning processes are most likely to occur when students create their own objects and link them to the abstract concepts and the pictures or visuals presented to them. This also allows students to integrate and make connections between different learning experiences that they have went through at different times and contexts as well.

Unlike learning other Physics' conceptual areas, when trying to master electromagnetism, students' create mental models that include abstractions and invisible factors for which they have no real life exposure to [5]. Presenting learning materials through different methods can be very useful to the students' learning experience. The abstract concepts can be presented not only in words and visuals but also can be made clear when students build real working models to fully understand the nature of the scientific phenomena. Therefore, it can be argued that students will better learn and retain the knowledge when they actively get involved in the learning process.

In this work the students built their own brushless DC motor from its' basic components. The students could see how the electromagnets are created and operated; they can also visualize how the energy was converted from an electric form to a mechanical rotational form.

The Engineering Ideas Clinic is an initiative that is supported by the Dean of Engineering office to supplement the traditional engineering curriculum with open-ended activities designed to spark student selflearning and exploration. Through Ideas Clinic activities, students learn good engineering practices by experimenting with real-world engineering problems; they gain an appreciation for the connections between 
courses in their curriculum; and they exercise their creativity, judgment and problem solving skills while acquiring soft skills such as communication and team work. Most importantly, the activities provide students with a breadth of hands-on experiences in an enjoyable, and safe, environment [6].

In this paper, the authors will share the design of the "Electromechanical Devices \& Power Processing" course; their experience in designing, implementing and running the activity; feedback from students and next steps.

\section{Electromechanical Devices \& Power Processing Course}

The Electromechanical Devices and Power Processing course ME269 is a core course for second year Mechanical students. The students have taken a linear circuits course in their first year- GenE123; however, GenE123 does not include any electromagnetism or physics components. Hence, the whole concept of electromagnetism is introduced to the students in $\mathrm{ME}$ 269 and they need to master this concept as it forms the foundation for all the energy conversion machines studied in the course. It was noticed by previous course instructors that the students couldn't visualize or imagine this abstract concept. In previous iterations of the course instructors have used animations and simulations to help the students get the main idea behind the concept, yet the students were not able to visualize it.

\subsection{Course Overview}

The course is composed of six main chapters in addition to a review chapter on circuits. The main topics in this course are: Three Phase Circuits; Magnetic Circuits; Transformers; Synchronous Machines; Induction Machines; and DC Machines. For each of the machines studied in this course the students learn about its principle of operation, physical construction and some performance measures. This makes the course very concepts heavy and busy with new topics and applications. There are several teaching and learning components in the course: three hours lectures per week, two hours tutorial per week and six three-hour labs per term, hence it is very challenging to add more learning activities to the course. But the course instructor saw the prototype of the Brushless DC motor clinic activity and decided that it will be very useful to include it in the course as an optional activity for students who choose to have some hands on experience. The activity was offered to the students on the last week of classes after the scheduled labs were finished during the lab time slot.

\section{Activity Description}

In this course the students are already split to two tutorial sections. Within each tutorial section the students selfselected their own teams; each team is composed of three students.

In this activity the students' teams:

- Learned safe work practices in a laboratory setting.

- Experimented with a practical application of principles of electromagnetism.

- Constructed a Brushless DC motor.

- Verified the winding connection of the DC motor

Below is a brief description of the activity

1- Each team is given a kit that included the building blocks of the DC motor:

a. Rotor (that is pre-manufactured by the technical staff members at the Mechanical and Mechatronics Department).

b. Stator body: one slice of a plumbing PVC pipe in which holes were drilled on its' circumference to fasten the electromagnets/bolts to the stator, there are two extra drilled holes to allow the wires in and out.

c. Nine bolts to wind the three phases on.

d. Some screws to fasten the bolts in the stator body.

e. Color coded wire to wind around the bolts to form the electromagnets.

f. A PVC stator cover

2- A brief set of ill-defined instructions is also made available to the students, these instructions include:

a. The wound stator figure- shown in Figure 1.

b. The fully assembled motor- shown in Figure 2.

c. The manual switch box to be used in verifying the motor winding connection- shown in Figure 3.

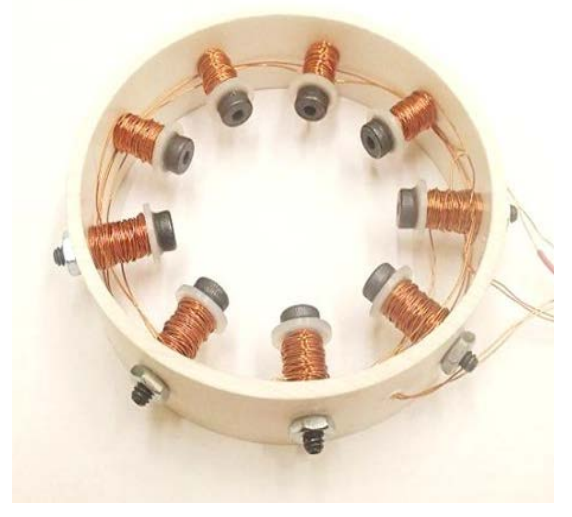

Fig. 1.a. Wound stator as it appears in the instructions. 


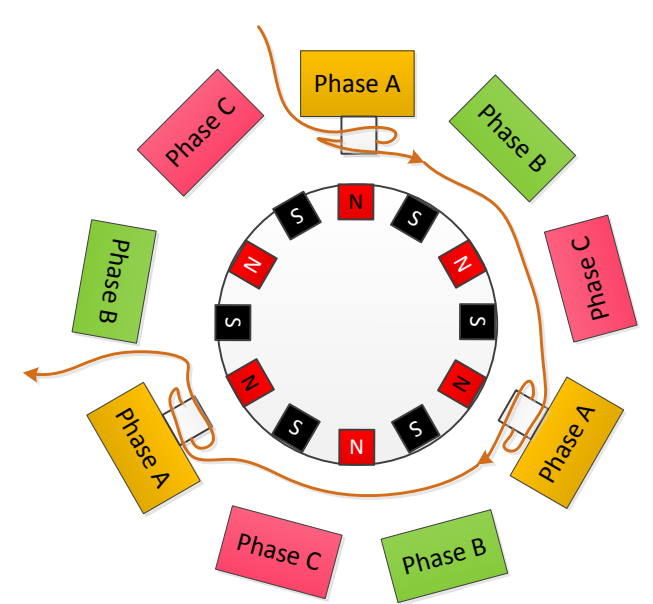

Fig.1.b. Schematic diagram of a simple BLDC motor

d. Diagrams that show the sequence of firing the electromagnets for a $1 / 3$ rotation on a simple 3 phase BLDC motor as seen in Figure 4.

e. An important note that all the coils need to be wound in the same direction.

3- After the students wind the stator windings, they test their motor by verifying the switching sequence using manual switching box shown in Figure 3 .

4- The students then test their motor by connecting it to a power supply that is pre-programmed to trigger the three phases such as the motor rotates in one direction.

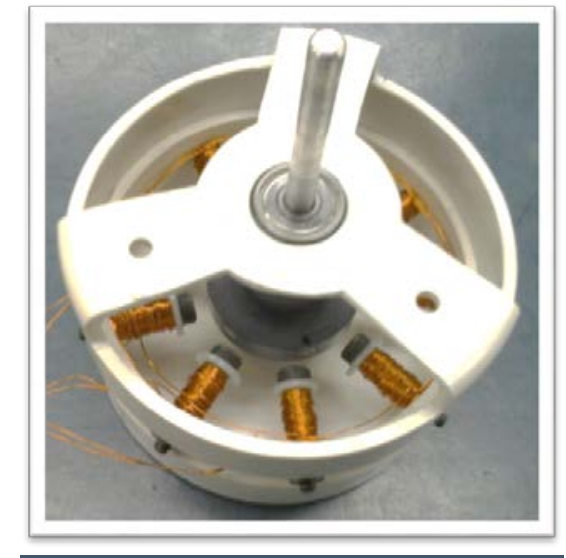

Fig. 2. Assembled BLDC motor

5- Finally the students submit a reflection on how the activity went, in this reflection they:

a. Explain how to reverse the motor's direction of rotation.

b. Reflect on the most challenging part of the activity.

c. Reflect on the most significant learning that they have encountered during the activity.

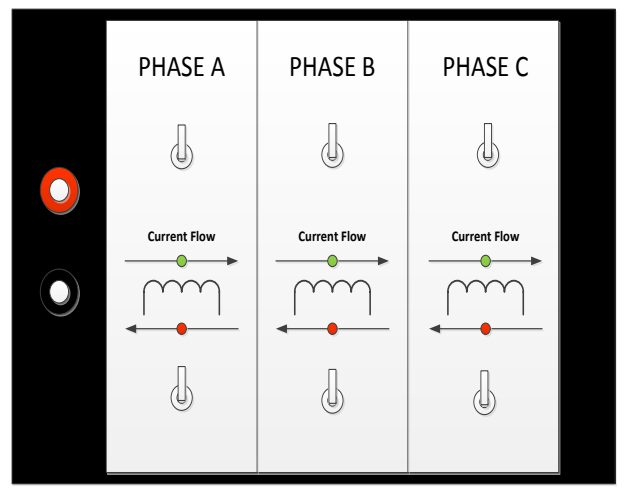

Fig. 3. Manual Switch box

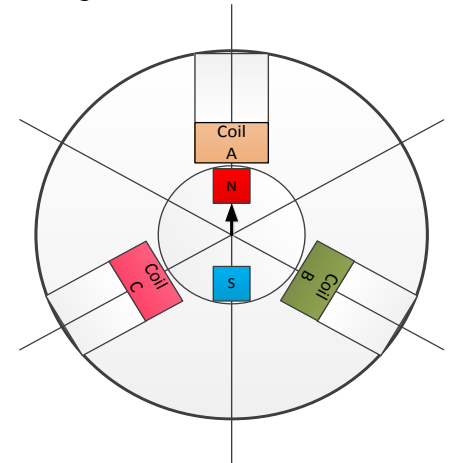

Fig. 4.a. Coil A current direction (S pole)

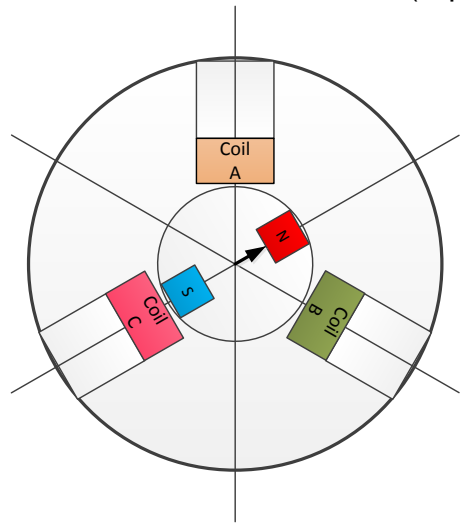

Fig. 4.b. Coil $\mathrm{C}$ current direction ( $\mathrm{N}$ pole)

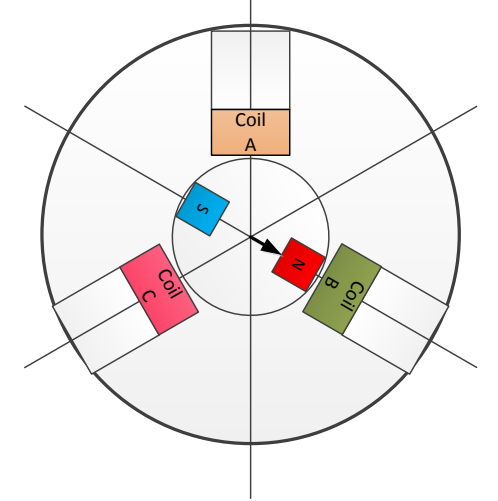

Fig. 4.c. Coil B current direction (S pole) 


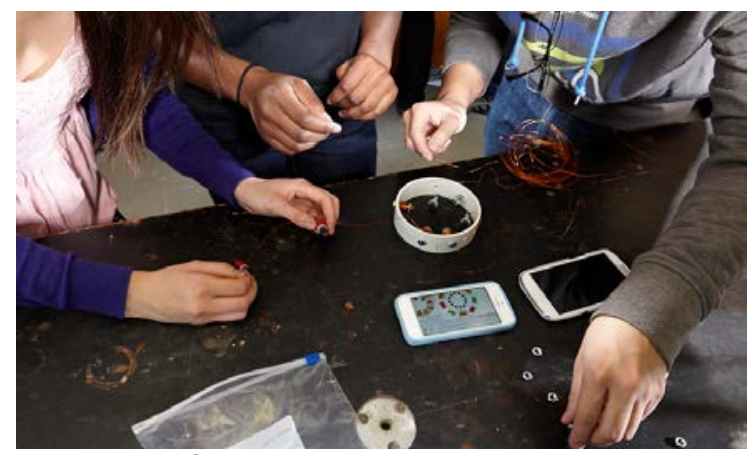

Fig. 5. Students engaged in building their motor

\section{Discussion}

Fall 2014 was the first term this activity was piloted; hence there was lots of lessons learned for the course instructor and the technical team.

- This was an optional activity but most of the students attended (119 out of 121), they were all excited and stayed in the lab. For the full two hours.

- Some of the groups took it further and wanted to operate their motors as generators; they rotated the rotor and watched the waveform they have generated on the oscilloscope.

- It was noticed that the students were very much engaged in the activity and excited about finishing it and making their motor work, see a photo of one of the teams having their instructions up and trying to figure out the best way to construct their motor.

- It was also noticed that it would have been better if we have teams of two not three so that they all have a say in the activity and no one is idle at any time.

- There was a long line up at the testing station, so for the following iteration of the activity, that was done in winter 2015 for Electrical and Computer first year students, we had more testing stations manned by knowledgeable technical staff and TAs.

- Looking at the students' reflections, they found it challenging to keep the wires from tangling and they shared their solutions to this challenge.

- They also found it very useful to see how the change in current's direction will change how their motor operates.

- They found that all the coils need to be wound in the same direction for the motor to rotate properly. While this information was mentioned in the instructions, yet they haven't noticed it. Therefore, they found that they should have examined the instructions thoroughly in order not to waste time rewinding the electromagnets.

- They found this activity very different than a typical lab where they have determined instructions and very expected results.

- Another difference that they have found was that in the lab they are mainly dealing with the machines as black boxes to model them or test their performance, but in this activity they dug deep in the machine's construction which allowed them to have a better understanding of its theory of operation.

\section{Conclusion and Future work}

The authors of the paper found this activity a success especially for a pilot. In this activity the students were given a kit of wires, stator and rotor where they constructed their own motors and tested them. We were able to see the excitement and the high fives throughout the activity; the energy level was high and the students were able to make connections between the abstract theory and the motor they built. This activity was also implemented for first year Electrical and Computer Engineering students the following term and there is a plan to us it for Mechatronics students in Spring 2015. Another plan is to move it up in the term so that the students can have an assignment on modeling the motor they have built.

\section{References}

[1] Dori, Y. J., \& Belcher, J. (2005). Learning electromagnetism with visualizations and active learning, in J. K. Gilbert (Ed.), Visualization in science education (pp. 187-216). Netherlands: Springer.

[2] Ibáñez, María Blanca, et al. "Experimenting with electromagnetism using augmented reality: Impact on flow student experience and educational effectiveness." Computers \& Education 71 (2014): 1-13.

[2] Stickel, Micah. "Teaching Electromagnetism with the Inverted Classroom Approach: Student Perceptions and Lessons Learned." Proceedings 2014 ASEE Annual Conference \& Exposition. 2014

[4] R. Mayer "Nine Ways to Reduce Cognitive Load in Multimedia Learning”, Journal of Educational Psychologist, 38(1), pps. 43-52, 2003

[5] Ding, L., R. Chabay, B. Sherwood, and R. Beichner, "Evaluating an electricity and magnetism assessment tool: Brief electricity and magnetism assessment,” in Phys. Rev. Special Topics - Phys. Ed. Research, 2 (010105), pps. $1-7,2006$.

[6] https://uwaterloo.ca/engineering-ideas-clinic/ 